\title{
PENGARUH PEMBERIAN BOOKLET PENATALAKSANAAN KEGAWATDARURATAN CHOOKING PADA TOODLER TERHADAP PENGETAHUAN IBU
}

\author{
Miranti Florencia Iswari ${ }^{1}$ \\ ${ }^{1}$ Fakultas Ilmu Kesehatan, Institut Ilmu Kesehatan \\ dan Teknologi Muhammadiyah Palembang \\ Email: umydirajuna@gmail.com
}

\begin{abstract}
ABSTRAK
Latar Belakang : Kondisi kegawatdaruratan pernapasan akibat tersedak dapat dicegah apabila orang yang berada di sekitar anak tersebut mampu melakukan penanganan yang benar. Pendidikan kesehatan perlu dilakukan untuk meningkatkan pengetahuan ibu dalam menangani anak saat tersedak yaitu dengan melakukan pertolongan pertama, salah satunya dengan media booklet. Tujuan : penelitian ini bertujuan untuk mengetahui adanya pengaruh pemberian booklet penanganan kegawatdaruratan pada toodler terhadap pengetahuan ibu. Metode : Penelitian ini dilakukan dengan metode quasi eksperimen yang menggunakan rancangan two group pre and post test design. Variabel independen dalam penelitian ini adalah pemberian booklet penanganan kegawatdaruratan chooking pada toodler dan variabel dependen adalah pengetahuan ibu. Sampel dalam penelitian ini adalah ibu yang memiliki anak toodler berjumlah 30 orang. Hasil : menunjukkan bahwa adanya perbedaan nilai sebelum dan sesudah intervensi melalui uji wilcoxon diperoleh $\mathrm{p}$ value $=0.000$, karena nilai $\mathrm{p}<0,05$, maka secara statistik dapat dikatakan ada pengaruh pemberian booklet penanganan kegawatdaruratan chooking pada toodler terhadap pengetahuan ibu. Saran: Diharapkan hasil penelitian ini dapat menjadi salah satu rencana intervensi tambahan bagi petugas kesehatan dalam memberikan pendidikan kesehatan bagi masyarakat.
\end{abstract}

Kata kunci: booklet penanganan chooking, toodler, pengetahuan ibu

\begin{abstract}
Background : Emergency respiratory conditions due to choking can be prevented if the people around the child are able to do the correct treatment. Health education needs to be done to increase mother's knowledge in dealing with children when choking, namely by doing first aid, one of which is booklet media. Aim : this study aims to determine the effect of giving emergency handling booklets to toddlers on mother's knowledge. Methods: This study was conducted using a quasiexperimental method using a two group pre and post test design. The independent variable in this study was the provision of booklets for handling emergency chooking to the toddler and the dependent variable was mother's knowledge. The sample in this study were mothers who have toodler children totaling 30 people. Results: showed that there was a difference in the value before and after the intervention through the Wilcoxon test obtained $p$ value $=0.000$, because the $p$ value $<0.05$, statistically it can be said that there is an effect of giving booklets for handling emergency chooking on toddlers on mother's knowledge. Suggestion: It is hoped that the results of this study can be one of the additional intervention plans for health workers in providing health education for the community.
\end{abstract}

Keywords: chooking handling booklet, toodler, mother's knowledge 


\section{PENDAHULUAN}

Gawat darurat adalah suatu keadaan yang dapat mengancam nyawa sehingga memerlukan penanganan atau tindakan segera untuk menghilangkan ancaman nyawa korban (Musliha, 2010). Hal yang harus dilakukan terlebih dahulu untuk mengidentifikasi masalah-masalah yang dapat mengancam hidup korban dengan melakukan survey primer, yaitu (C: sirkulasi/circulation), (A: jalan napas/airway), (B: breathing/pernapasan) (Krisanty, et al., 2009).

Keadaan kedaruratan akibat kemasukan benda asing (tersedak/choking) sangat membutuhkan pertolongan dengan segera, mengingat benda tersebut akan mengganggu fungsi vital dalam tubuh seperti mengganggu jalan napas atau aliran udara ke paru-paru (Hidayat, 2008).

Data tentang kejadian tersedak pada anak di Indonesia belum ada, namun telah banyak kejadian tersedak terjadi, di antaranya kasus tersedak di Tegal pada 25 November 2015 yang disebabkan karena tersedak jajanan cimol. Sebelum di bawa ke rumah sakit. Balita ini sempat diberikan pertolongan dengan memijat-mijat lehernya selama 15 menit, namun tindakan ini salah. Akibatnya, terjadi gagal napas karena saluran napas tersumbat dan menyebabkan kematian (Sindonews, 2015).

Media yang digunakan pada penelitian ini adalah booklet. Menurut penelitian yang dilakukan oleh Artini dkk (2014) tentang Perbedaan Pengaruh pendidikan kesehatan menggunakan media leaflet dengan booklet terhadap tingkat pengetahuan masyarakat di desa trangsan gatak sukoharjo, hasil penelitian menunjukkan adanya perbedaan pengetahuan sebelum dan sesudah dalam pendidikan kesehatan mencerminkan bahwa media booklet lebih menarik bagi responden sehingga lebih mempermudah dalam memahami materi. Hal tersebut didasari dalam penelitian Zulaekah (2012) didapatkan hasil bahwa menggunakan booklet dapat meningkatkan pengetahuan tentang gizi. Penelitian Sulistiyani, dkk (2020) juga menunjukkan ada pengaruh pendidikan kesehatan dengan media booklet tentang penanganan tersedak pada anak terhadap tingkat pengetahuan kader posyandu di Desa Karangsari
Berdasarkan latar belakang diatas peneliti tertarik untuk meneliti pengaruh pemberian booklet penanganan kegawatdaruratan choking pada toddler terhadap pengetahuan ibu

\section{METODE PENELITIAN}

Penelitian ini merupakan jenis penelitian kuantitatif. Sampel pada penelitian ini adalah ibu yang memiliki anak usia 1-3 tahun di PAUD SAKIRA Palembang. Pengambilan sampel pada penelitian ini sebanyak 30 responden dengan Kriteria inklusi dalam penelitian ini adalah Ibu yang memiliki anak usia 1-3 tahun, bersedia menjadi responden dalam penelitian ini.

Instrumen yang digunakan dalam penelitian ini adalah kuesioner berupa sejumlah pertanyaan untuk memperoleh informasi dari responden. Instrumen pengetahuan ibu menggunakan kuesioner pada jurnal knowledge and attitude of primary school teachers regarding choking's first aidin Erbil yang telah dibakukan oleh 7 ahli yang berkompeten di bidangnya dengan Cronbach's alpha 0,89. Namun, kuesioner ini akan tetap dilakukan uji validitas dan reliabilitas. Kuesioner pengetahuan terdiri dari 12 pernyataan tentang pengetahuan dengan jawaban benar diberi nilai 1 dan jawaban salah diberi nilai 0 .

\section{HASIL PENELITIAN}

\section{Analisa Univariat}

Berdasarkan karakteristik responden dari 30 responden yaitu nilai median usia responden 26.00. Usia minimun responden 19 tahun dan usia maksimum 32 tahun dengan standar deviasi 3.571.

Pada hasil analisis univariat dapat dilihat dari grafik 5.1 menunjukan bahwa pengetahuan ibu sebelum dilakukan intervensi terendah dimiliki oleh responden 5, 16, 20 dengan nilai pengetahuan 5 dan tertinggi dimiliki oleh responden 13 dengan nilai pengetahuan 10. Nilai pengetahuan setelah dilakukan intervensi terendah dimiliki oleh responden 16 dengan nilai pengetahuan 5 dan tertinggi dimiliki oleh responden $2,3,7,8,11$, $13,14,15,18,21,22,23,24,25,26,27,28$, 29 dengan nilai pengetahuan 12 dan terdapat satu responden yang tidak ada perubahan 
pengetahuan antara sebelum dan setelah intervensi yaitu pada responden 16 dengan nilai pengetahuan 5 (Gambar 1).

Pada hasil analisis bivariat dapat dilihat pada tabel 5.3 dari total 30 responden didapatkan hasil penelitian bahwa adanya perbedaan nilai sebelum dan sesudah intervensi menggunakan Uji Wilcoxon diperoleh $\mathrm{p}$ value $=0.000$, karena nilai $\mathrm{p}<$ 0,05, maka secara statistik dapat dikatakan ada pengaruh pemberian Booklet penanganan kegawatdaruratan Choking pada Toddler terhadap pengetahuan ibu (Gambar 2).

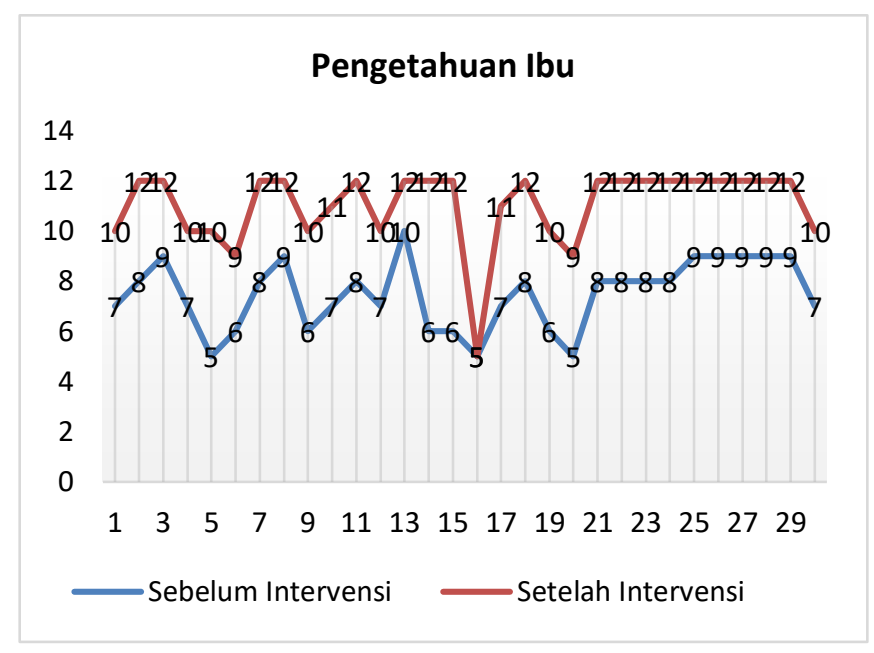

Gambar 1.

\begin{tabular}{llcccc}
\hline No & \multicolumn{1}{c}{ Variabel } & $\begin{array}{c}\text { Media } \\
\mathbf{n}\end{array}$ & Min & Max & P Value \\
\hline 1. & $\begin{array}{l}\text { Pengetahuan Ibu } \\
\text { sebelum intervensi }\end{array}$ & 8.00 & 5 & 10 & 0.000 \\
& $\begin{array}{l}\text { Pengetahuan ibu } \\
\text { setelah intervensi }\end{array}$ & 12.00 & 5 & 12 & \\
2. & & & & & \\
\hline
\end{tabular}

Gambar 2.

\section{PEMBAHASAN}

Hasil uji Wilcoxon antara pre test dan post test pengetahuan ibu diperoleh $\mathrm{p}$ value $=$ 0.000 , karena nilai $\mathrm{p}<0,05$ maka secara statistik dapat dikatakan ada pengaruh pemberian booklet penanganan kegawatdaruratan chooking pada Toddler terhadap pengetahuan ibu.

Berdasarkan penelitian yang di lakukan oleh Pandegirot (2019) bahwa hasil kegiatan menunjukan bahwa terjadi peningkatan pengetahuan ibu mengenai penanganan kegawatdaruratan Chooking pada Toddler berdasarkan hasil pre-test dan post test.
Sejalan dengan penelitian Sumarningsih (2015) dalam kegiatan tentang memberikan edukasi mengenai "Pengaruh edukasi keluatga tentang pencegahan dan penanganan tersedak pada anak terhadap pengetahuan dan ketrampilan keluarga" bahwa terdapat pengaruh yang signifikan pemberian penyuluhan Kesehatan terhadap pengetahuan. Hasil penelitian ini sejalan dengan penelitian Kusniawati (2020) tentang pengaruh pemdidikan kesehatan pertolongan pertama tersedak dengan google form dan phantom pada orang tua di TK taman sukaria terhadap kemampuan keluarga. Hasil penelitian terdapat perbedaan yang signifikan antara keterampilan orang tua sebelum dan sesudah dilakukan pendidikan kesehatan pertolongan pertama tersedak yakni nilai P Value $0,000(<\alpha 0,05)$.

Media pendidikan kesehatan adalah alat bantu pendidikan (audio visual aids/AVA). Berdasarkan fungsinya sebagai penyaluran pesan-pesan kesehatan (media). Media Pendidikan Kesehatan yang dipakai dalam penelitian ini adalah Booklet. Booklet ialah suatu media untuk menyampaikan pesan-pesan kesehatan dalam bentuk buku, baik tulisan maupun gambar Notoatmodjo (2011).

Peran perawat dalam penyuluhan Kesehatan tentang penanganan tersedak sangat diperlukan untuk mencegah terjadinya tersedak. Informasi melalui Booklet dibutuhkan untuk penanganan yang cepat dan tepat. Sehingga masyarakat tidak hanya sadar, tahu dan mengerti tetapi juga mau dan bisa melakukan satu anjuran yang ada hubungan dengan Kesehatan yaitu tentang penanganan kegawatdaruratan Chooking pada Toddler sehingga akan meningkatkan pengetahuan dan ketrampilan ibu dalam melakukannnya (Surmaningsih,2015).

Peran perawat dalam upaya meningkatkan pengetahuan Ibu mengenai penanganan kegawatdaruratan tersedak pada anak dengan cara memberikan pendidikan dan penyuluhan kesehatan serta pemberian Booklet kepada ibu dalam rangka meningkatkan pengetahuan dan ketrampilan dalam menangani kejadian tersedak pada anak agar ibu dapat melakukan penanganan tersedak pada anak dengan tepat dan sesuai dengan anjuran tenaga kesehatan. Sehingga ibu bisa mengenali masalah kesehatan dan dapat mengambil keputusan untuk melakukan tindakan yang tepat bagi anak yang mengalami tersedak (Surmaningsih, 2015). 
Berdasarkan hal tersebut maka peneliti berasumsi bahwa pengetahuan ibu terhadap kejadian tersedak pada anak menjadi perhatian yang sangat penting karena ibu sangat berperan penting dalam pengawasan setiap aktivitas anak. Ibu yang kurang pengetahuan terhadap penanganan tersedak dikhawtirkan mengakibatkan perlakuan yang salah sehingga malah mengakibatkan kesalahan atau ketidaktahuan dalam mengangani anak yang tersedak. Salah satu upaya yang tepat adalah dengan pemberian Booklet penanganan kegawatdaruratan Chooking pada Toddler Maka penting sekali edukasi pemberian Booklet penanganan kegawatdaruratan Chooking pada Toddler untuk meningkatkan pengetauan Ibu.

\section{KESIMPULAN}

Berdasarkan hasil penelitian yang telah dilakukan dapat disimpulkan bahwa terdapat perbedaan nilai sebelum dan sesudah intervensi menggunakan Uji Wilcoxon diperoleh $\mathrm{p}$ value $=0.000$, karena nilai $\mathrm{p}<$ 0,05, maka secara statistik dapat dikatakan ada pengaruh pemberian Booklet penanganan kegawatdaruratan Chooking pada Toddler terhadap pengetahuan ibu.

Perlu di pertimbangkanuntuk melakukan Pendidikan Kesehatan di PAUD SAKIRAPlaju Palembang untuk memberian Booklet penanganan kegawatdaruratan Chooking pada Toddler dapat meningkatkan pengetahuan orang tua dalam menangani tersedak pada anak

\section{DAFTAR PUSTAKA}

Daryanto. (2016). Media Pembelajaran. Yogyakarta: Gava Media.

Drago, D. A. (2013). Living Safely, Aging Well. United States Of America: John Hopkins University Press.

Hidayat, A. A. (2008). Pengantar Ilmu Kesehatan Anak untuk Pendidikan Kebidanan. Jakarta: Salemba Medika.

Jahja, Y. (2011). Psikologi Perkembangan. Jakarta: Prenadamedia Group.
Musliha. (2010). Keperawatan Gawat Darurat. Yogyakarta: Nuha Medika.

N, Dewi. K. (2013). Buku Ajar Dasar-dasar Keperawatan Gawat Darurat. Jakarta: Salemba Medika.

Nasir, A., Muhith, A., \& Ideputri, M. E. (2011). Buku Ajar Metodologi Penelitian Kesehtan: Konsep Pembuatan Karya Tulis dan Thesis untuk Mahasiswa Kesehatan. Yogyakarta: Nuha Medika.

Notoatmodjo, S. (2011). Kesehatan Masyarakat Ilmu dan Seni. Jakarta: Rineka Cipta.

Nurs, N. M., \& Effendi, F. (2012). Pendidikan dalam Keperawatan. Jakarta: Salemba Medika.

Oman, K. S., Mc-Lain, J. K., \& Scheetz, L. J. (2008). Panduan Belajar Kperawatan Emergensi. Jakarta: EGC.

Pandegirot, Juliana Sisca. Pengaruh penyuluhan Kesehatan Tentang Penanganan Tersedak Terhadap Pengetahuan Ibu Menyusui. Jurnal Keperawatan Volume 7 Nomor 2. November 2019

Pavitt, M. J., Nevett, J., Swanton, L. L., Hind, M. D., Polkey, M. I., Green, M., \& Hopkinson, N. S. (2017). London ambulance source data on choking incidence for the calendar year 2016: an observational study, 2-5. https://doi.org/10.1136/bmjresp-2017000215

Putra, D. S., \& dkk. (2014). Keperawatan Anak dan Tumbuh Kembang. Yogyakarta: Nuha Medika

Rahayu, R. P. (2014). Pengaruh Pendidikan Kesehatan Terhadap Tingkat Pengetahuan Orangtua Dalam Menangani Anak Tersedak Di Desa Kedungsoka Puloampel Serang Banten. Skripsi. 
Rayyana, P. (2013). Buku PintarKehamilan PerawatanBayi/Anak Usia Emas. Yogyakakarta: Kaldron.

Sujarweni, V. W. (2016). Metodologi Penelitian Keperawatan. Yogyakakarta: Gava Media.

Sumarningsih, D (2015) Pengaruh Edukasi Keluarga Tentang pencegahan dan Penanganan tersedak Pada Anak Terhadap pengetahuan dan ketrampilan keluarga Dukuh Ngebel Rt 09 Taman tirto Kasihan Bantul Hal 9

Susilaningrum, R., Utami, S., \& Nursalam. (2013). Asuhan Keperawatan Bayi dan Anak Untuk Perawat dan Bidan Edisi II. Jakarta: Salemba Medika.

Swasanti, N., \& Putra, W. S. (2013). pertolongan Pertama Pada Anak Sakit : Panduan Penangan Pertama Ketika Anak Sakit atau Mengalami Kecelakaan. Yogyakarta: Kata Hati.

Thygerson, A. (2011). Pertolongan Pertama Edisi ke Lima. Indonesia: Erlangga 
